\title{
Quality of life in patients with multiple sclerosis and urinary disorders: Reliability and validity of Turkish-language version of Incontinence Quality of Life Scale
}

\author{
Sibel Eyigor, MD; ${ }^{*}$ Hale Karapolat, MD; ${ }^{1}$ Yesim Akkoc, MD; ${ }^{1}$ Hilal Yesil, MD; ${ }^{1}$ Ozgül Ekmekci, MD $^{\mathbf{2}}$ \\ ${ }^{1}$ Physical Medicine and Rehabilitation Department and ${ }^{2}$ Neurology Department, Ege University, Izmir, Turkey
}

\begin{abstract}
Incontinence is one of the most frequently encountered problems in multiple sclerosis (MS), and it has a negative effect on the daily lives of patients. Therefore, it is important to investigate this complaint and start appropriate treatment early. The aim of our study was to demonstrate the validity and reliability of the Turkish-language Incontinence Quality of Life Scale (I-QOL) in patients with MS. We included 37 patients with MS in this study. For analysis of test-retest reliability, we administered the Turkish-language version of I-QOL developed by a "translation-back translation" method to patients on the day of admission and 1 week after admission. To assess validity, we also evaluated patients with the Multiple Sclerosis Quality of Life Scale (MQOL-54) and Expanded Disability Status Scale (EDSS). We calculated the intraclass correlation coefficient of the I-QOL (total and all subscores) as 0.88 to 0.91 and the Cronbach alpha score as 0.88 to $0.91(p<0.05)$. We found a significant correlation among all subscores of I-QOL and physical and mental subscores of MQOL-54 and EDSS $(p<0.05)$. Our study has demonstrated the internal consistency and reliability of the I-QOL in the Turkish language in patients with MS.
\end{abstract}

Key words: Expanded Disability Status Scale, incontinence, Incontinence Quality of Life Scale, multiple sclerosis, Multiple Sclerosis Quality of Life Scale, quality of life, rehabilitation, reliability, Turkish language, urinary disorders, validity.

\section{INTRODUCTION}

Incontinence restricts social relations and deteriorates emotional and psychological well-being. Embarrassment and lack of self-confidence are also among the negative effects of incontinence. The International Scientific Committee has recommended investigating the quality of life (QOL) for incontinence sufferers [1]. Incontinence is also one of the most frequently encountered problems in multiple sclerosis (MS) and has a negative effect on the daily lives of patients [2]. Therefore, it is important to investigate this complaint and start appropriate treatment early. Different scales (International Consultation on Incontinence Questionnaire Short Form, Qualiveen) are used in the evaluation of incontinence in patients with MS [3-4]. The Incontinence Quality of Life Scale (I-QOL) is a questionnaire used to evaluate the effect of incontinence on QOL. Its validity and reliability have been proven [5], and it has 15 different language versions [6]. Furthermore, the I-QOL has also been shown to be a validated and reliable questionnaire in patients with neurological bladder dysfunction, including MS [7]. The validity and reliability of the questionnaire in the Turkish language has not been

\footnotetext{
Abbreviations: EDSS = Expanded Disability Status Scale, ICC = intraclass correlation coefficient, I-QOL = Incontinence Quality of Life Scale, MQOL-54 = Multiple Sclerosis Quality of Life Scale, MS = multiple sclerosis, QOL = quality of life, SF-36 = 36-Item Short Form Health Survey.

*Address all correspondence to Sibel Eyigor, MD; Physical Medicine and Rehabilitation Department, Ege University, 35100 Bornova, Izmir, Turkey; +90-232-3903687; fax: +90232-3881953. Email: eyigor@hotmail.com

DOI:10.1682/JRRD.2009.08.0132
} 
determined, and since validity and reliability in the languages in which it is to be applied are important, the objective of our study is to demonstrate the validity and reliability of the I-QOL in the Turkish language in patients with MS.

\section{MATERIALS AND METHODS}

\section{Patients}

The study included 37 patients with MS monitored in the Neurology Department outpatient clinic between September 2008 and May 2009 and assigned to Physical Medicine and Rehabilitation Department for rehabilitation (Ege University, İzmir, Turkey). Inclusion criteria included $>18$ years old, clinically definite MS diagnosis (Poser et al. criteria [8]), knowledge of their MS diagnosis, and stable urinary disorders (no changes made to the bladder emptying method or to their medications). Exclusion criteria included congenital urological disorders, bladder cancer, concomitant neurological illness, exacerbation in the past month, urinary disorders unrelated to MS, and difficulty answering the questionnaire because of language or cognitive limitations.

\section{Translation Process}

Three Turkish physical medicine and rehabilitation doctors proficient in English translated the I-QOL into Turkish. They met to determine the translation that best reflected the meaning of the English items. Two official linguists uninformed about the original I-QOL separately performed English back-translations from Turkish (one native English speaker that can speak Turkish and one teacher of English literature who lived in England for 15 years). Finally, all five translators gathered to discuss and decide on the translations. We compared this final Turkish-language version with the original English version, which appeared to be identical. We delivered this Turkish-language version to 20 patients with spinal cord injury; we asked whether they could understand all items of the Turkish-language I-QOL. None of the patients in this initial group reported any problem understanding any item of the I-QOL.

\section{Measures}

Thirty-seven patients completed the I-QOL during their first examination. We recorded the demographic (age, sex, education, and occupation) and clinical (MS onset age, duration, and course) data of patients from patient files and face-to-face interviews. We also questioned patients' voiding patterns, urinary symptoms, and frequencies of urinary incontinence (occurrences per day). In addition, we evaluated patients using the Expanded Disability Status Scale (EDSS) total score, the EDSS bladder and bowel subscore, and the Multiple Sclerosis Quality of Life Scale (MQOL-54). One week after the first assessment, the 37 patients completed the I-QOL for a second time to check for test-retest reliability. We chose an interval of 1 week to minimize the effect of time on memory and because of the possibility of substantial changes in the neurological condition, which could interfere with the results of the study. The methods used for patient evaluation are described next.

\section{Incontinence Quality of Life Scale}

The I-QOL contains 22 items, each with a 5-point Likert-type response scale, yielding a total score and three subscale scores (avoidance behavior, psychosocial impact, and social embarrassment). Higher I-QOL scores indicate better levels of QOL [5].

\section{Multiple Sclerosis Quality of Life Scale}

The MQOL-54 combines the 36 items from the 36Item Short Form Health Survey (SF-36) and 18 additional items specific to MS into 14 domains. Physical health composite and mental health composite summary scores can be derived from a weighted combination of scale scores [9-10].

\section{Expanded Disability Status Scale}

The EDSS assesses impairment and disability through ratings of eight functional systems using neurological examination of a patient's walking ability. In this scale, which consists of a 0.5 interval and 20 steps, 0 represents normal neurological pressure and 10 represents death due to MS [11].

\section{Statistical Analysis}

We entered data into the SPSS package, version 16.0 (Chicago, Illinois). We used descriptive statistics to characterize the sample. We used the intraclass correlation coefficient (ICC) to assess item-specific test-retest reliability of the I-QOL. For the consistency of the whole scale, we performed reliability analysis, calculated Cronbach alpha coefficients, and assessed item total correlation. We assessed correlation between subdivisions of scales 
and other parameters determined by Pearson's correlation analysis. We considered a $p$-value below 0.05 statistically significant.

\section{RESULTS}

The study included 37 patients with MS. Table 1 shows demographic and clinical data of patients and the averages of the total scores and subscores of the Turkishlanguage I-QOL. Of the patients, 25 had an EDSS score of between 0 and 4, 6 had a score of between 4.5 and 5.5, and 6 had a score of between 6 and 6.5.

We calculated the total mean I-QOL score and ICC of all subscores of I-QOL as 0.88 to 0.91 and the Cronbach alpha score as 0.88 to 0.91 ( $p<0.05$, Table 2). We found a significant correlation between all subscores of the I-QOL and physical and mental subscores of the MQOL-54 ( $p<0.05$, Table 3).

We found the distribution of urinary symptoms as follows: 24 patients had urgency, 20 had urge incontinence, 8 had hesitancy, and 5 had nocturia. We found incontinence frequencies of patients with symptoms of incontinence as follows: 12 patients had 1 to 2 occurrences per day, 6 had 3 to 4 occurrences per day, and 2 had $5+$ occurrences per day. We found voiding pattern of the patients as follows: 12 patients used clean intermit-

Table 1.

Demographic and clinical data of patients with multiple sclerosis (MS) $(n=37)$.

\begin{tabular}{lc}
\hline \multicolumn{1}{c}{ Demographic and Clinical Data } & Value \\
\hline Age, Mean \pm SD (range) & $38.19 \pm 11.65(20-62)$ \\
Sex: Female, $n(\%)$ & $16(81.1)$ \\
Education: University Degree, $n(\%)$ & $21(56.7)$ \\
Occupation: Retired + Housewife, $n(\%)$ & \\
MS & $29.16 \pm 9.34(16-51)$ \\
Onset Age, Mean \pm SD (range) & $27(73.0)$ \\
Duration (months), Mean \pm SD (range) & $119.49 \pm 9.34(5-312)$ \\
Course: Relapse/Remission, $n$ (\%) & \\
EDSS, Mean \pm SD (range) & $3.43 \pm 1.92(0-6)$ \\
Total & $1.57 \pm 1.39(0-5)$ \\
Bowel/Bladder & \\
I-QOL, Mean \pm SD (range) & $26.32 \pm 8.12(7.00-36.67)$ \\
Total & $26.92 \pm 8.87(8-40)$ \\
Avoidance and Limiting Behaviors & $33.35 \pm 10.45(8-45)$ \\
Psychosocial Impacts & $18.70 \pm 6.00(5-25)$ \\
$\quad$ Social Embarrassment & \\
\hline EDSS $=$ Expanded Disability Status Scale, I-QOL = Incontinence Quality of \\
Life Scale, SD = standard deviation.
\end{tabular}

Table 2.

Internal consistency and test-retest reliability of Turkish-language Incontinence Quality of Life Scale (I-QOL) $(n=37)$.

\begin{tabular}{lrc}
\hline \multicolumn{1}{c}{ I-QOL } & ICC & Cronbach Alpha \\
\hline Avoidance and Limiting Behaviors & 0.88 & 0.88 \\
Psychosocial Impacts & 0.89 & 0.88 \\
Social Embarrassment & 0.90 & 0.90 \\
\hline Total & 0.91 & 0.91 \\
\hline ICC = intraclass correlation coefficient. & & \\
\hline
\end{tabular}

tent catheterization, 24 had a normal voiding + urinary symptoms, and 1 used a diaper.

\section{DISCUSSION}

In our study, we concluded that the Turkish-language I-QOL is internally consistent and reliable in patients with MS. The I-QOL is capable of discriminating between different levels of perceived severity, use of medical services, and frequency of incontinent episodes, as well as different levels of stress test pad weight, a commonly used clinical outcome measure [5].

The present study confirmed the significant effect that urinary incontinence has on the QOL of patients with MS. Lower QOL was reported with the social embarrassment items, as was found in other studies [12]. It is very important that the I-QOL is used to determine the changes in patients' QOL arising from urinary incontinence and that the obtained data is used to help patients return to a normal social environment.

In the original study, we determined that the I-QOL's Cronbach alpha was between 0.87 and 0.95 , showing a high internal consistency, and similarly its ICC was between 0.87 and 0.95 , demonstrating the stability of scores $[5,13]$. The internal consistency was demonstrated to be 0.70 in the reliability studies of I-QOL, which has translations in 15 languages [6]. Similarly, test-retest reliability showed the I-QOL to be stable over time, with ICC values all greater than the recommended 0.70 [6]. We observed that the Cronbach alpha ranged from 0.79 to 0.93 in patients with neurogenic detrusor activity (spinal cord injury, $n=53$; MS, $n=6$ ) [7]. We concluded that the I-QOL demonstrated high internal consistency (0.88-0.91) and test-retest reliability (0.88-0.91) in patients with MS.

Because of the limited number of data elements used across these different studies, we demonstrated the validity of the I-QOL using known-groups classifications based on the urinary incontinence severity of the patients. 
Table 3.

Structural validity: correlation between Incontinence Quality of Life Scale and Multiple Sclerosis Quality of Life Scale (MQOL-54) $(n=37)$.

\begin{tabular}{|c|c|c|c|c|}
\hline \multirow[b]{2}{*}{ Results } & \multicolumn{4}{|c|}{ I-QOL } \\
\hline & $\begin{array}{c}\text { Avoidance and } \\
\text { Limiting Behaviors }\end{array}$ & $\begin{array}{l}\text { Psychosocial } \\
\text { Impacts }\end{array}$ & $\begin{array}{c}\text { Social } \\
\text { Embarrassment }\end{array}$ & Total \\
\hline \multicolumn{5}{|l|}{$\overline{\text { MQOL-54 }}$} \\
\hline Mental Health & $0.34^{\dagger}$ & $0.33^{\dagger}$ & $0.40^{\dagger}$ & $0.38^{\dagger}$ \\
\hline \multicolumn{5}{|l|}{ EDSS } \\
\hline \multicolumn{5}{|l|}{${ }^{*} p<0.05$} \\
\hline EDSS = Expanded Dis & & & & \\
\hline
\end{tabular}

I-QOL scores in all language versions were able to discriminate between levels of severity. The original study demonstrated that, except for bodily pain, all subscores of the I-QOL were associated with subscores of SF-36 $(r=$ 0.15-0.67) as well as with those of the Psychological Well-Being Schedule ( $r=0.18-0.62$ ) [5,13]. A study carried out in Slovakia found that for SF-36, the I-QOL was related to both physical and mental subscores [6]. We compared the MQOL-54 with the EDSS in the validity research of our study, and we observed a significant relationship between all subscores of the I-QOL and MQOL54 score and EDSS score. Therefore, we concluded that the I-QOL is a validated scale for patients with MS.

Inclusion of a relatively homogenous group (the majority of patients had a low EDSS score [0-4] and all patients in the study group consisted of patients with MS) and the large number of patients with MS may be considered strengths of our study. However, the generalizability of these results may be limited and may not reflect a naturalistic setting. The sample was predominantly female, limiting generalizability to men. However, women tend to report their symptoms more frequently than men, making this result unremarkable. We were unable to assess the responsiveness of the questionnaire because we did not consider the aim of the treatment as an intervention for urinary incontinence in patients with MS. Considering this, we are conducting a separate study to demonstrate the sensitivity to change in patients with MS. Nevertheless, a control group could provide additional benefits for assessing correlation and sensitivity to change. Addressing these limitations in future studies would be beneficial.

\section{CONCLUSIONS}

Our study has demonstrated the internal consistency and reliability of the Turkish-language I-QOL in patients with MS. I-QOL is easily self-administered and takes approximately 5 minutes for the average patient reading at a fifth-grade level to complete. We recommend that incontinence investigation in patients with MS, often ignored in clinical practice in our country, be made using the Turkish-language I-QOL, which is a comprehensible and clear scale.

\section{ACKNOWLEDGMENTS}

\section{Author Contributions:}

Study concept and design: S. Eyigor, H. Karapolat, Y. Akkoc. Acquisition of data: H. Yesil, O. Ekmekci.

Analysis and interpretation of data: S. Eyigor, H. Karapolat, H. Yesil, O. Ekmekci.

Drafting of manuscript: H. Karapolat, Y. Akkoc.

Critical revision of manuscript for important intellectual content:

S. Eyigor, H. Karapolat, Y. Akkoc.

Study supervision: S. Eyigor, H. Karapolat, Y. Akkoc.

Financial Disclosures: The authors have declared that no competing interests exist.

Funding/Support: This study was unfunded at the time of manuscript preparation.

Institutional Review: The local ethics committee of Ege University approved this study, and the authors obtained informed consent from all the patients that participated.

Participant Follow-Up: The authors do not plan to inform participants of the publication of this study. However, participants have been encouraged to check the study Web site for updated publications. 


\section{REFERENCES}

1. Abrams P, Anderson KE, Brubaker L, Cardozo L, Cottenden A, Denis LD, et al. Recommendations of International Scientific Committee: Evaluation and treatment of urinary incontinence, pelvic organ prolapse and feacal incontinence. In: Abrams P, Cardozo L, Wein AJ, Khoury S, editors. Incontinence. 2nd ed. Plymouth (MA): Health Publication Ltd; 2005. p. 1589-1630.

2. Fernández O. Mechanisms and current treatments of urogenital dysfunction in multiple sclerosis. J Neurol. 2002; 249(1):1-8. [PMID: 11954855]

DOI:10.1007/PL00007835

3. Costa P, Perrouin-Verbe B, Colvez A, Didier J, Marquis P, Marrel A, Amarenco G, Espirac B, Leriche A. Quality of life in spinal cord injury patients with urinary difficulties. Development and validation of Qualiveen. Eur Urol. 2001; 39(1):107-13. [PMID: 11173948]

DOI:10.1159/000052421

4. Hajebrahimi S, Corcos J, Lemieux MC. International consultation on incontinence questionnaire short form: Comparison of physician versus patient completion and immediate and delayed self-administration. Urology. 2004; 63(6):1076-78. [PMID: 15183953] DOI:10.1016/j.urology.2004.01.005

5. Wagner TH, Patrick DL, Bavendam TG, Martin ML, Buesching DP. Quality of life of persons with urinary incontinence: Development of a new measure. Urology. 1996; 47(1):67-71. [PMID: 8560665] DOI:10.1016/S0090-4295(99)80384-7

6. Bushnell DM, Martin ML, Summers KH, Svihra J, Lionis C, Patrick DL. Quality of life of women with urinary incontinence: Cross-cultural performance of 15 language versions of the I-QOL. Qual Life Res. 2005;14(8):1901-13. [PMID: 16155777] DOI:10.1007/s11136-005-5266-5

7. Schurch B, Denys P, Kozma CM, Reese PR, Slaton T, Barron R. Reliability and validity of the Incontinence Quality of Life questionnaire in patients with neurogenic urinary incontinence. Arch Phys Med Rehabil. 2007;88(5):646-52. [PMID: 17466735]

DOI:10.1016/j.apmr.2007.02.009

8. Poser CM, Paty DW, Scheinberg L, McDonald WI, Davis FA, Ebers GC, Johnson KP, Sibley WA, Silberberg DH, Tourtellotte WW. New diagnostic criteria for multiple sclerosis: Guidelines for research protocols. Ann Neurol. 1983; 13(3):227-31. [PMID: 6847134 DOI:10.1002/ana.410130302

9. Vickrey BG, Hays RD, Harooni R, Myers LW, Ellison GW. A health-related quality of life measure for multiple sclerosis. Qual Life Res. 1995;4(3):187-206. [PMID: 7613530] DOI:10.1007/BF02260859

10. Idiman E, Uzunel F, Ozakbas S, Yozbatiran N, Oguz M, Callioglu B, Gokce N, Bahar Z. Cross-cultural adaptation and validation of Multiple Sclerosis Quality of Life Questionnaire (MSQOL-54) in a Turkish multiple sclerosis sample. J Neurol Sci. 2006;240(1-2):77-80. [PMID: 16277993] DOI:10.1016/j.jns.2005.09.009

11. Kurtzke JF. Natural history and clinical outcome measures for multiple sclerosis studies. Why at the present time does EDSS scale remain a preferred outcome measure to evaluate disease evolution? Neurol Sci. 2000;21(6):339-41. [PMID: 11441569] DOI:10.1007/s100720070047

12. Renck-Hooper U, McKenna SP, Whalley D. Measuring quality of life in female urinary urge incontinence: Development and psychometric properties of the IQOLI. J Drug Assessment. 1998;1(1):41-48.

13. Patrick DL, Martin ML, Bushnell DM, Yalcin I, Wagner TH, Buesching DP. Quality of life of women with urinary incontinence: Further development of the incontinence quality of life instrument (I-QOL). Urology. 1999;53(1): 71-76. [PMID: 9886591] DOI:10.1016/S0090-4295(98)00454-3

Submitted for publication August 25, 2009. Accepted in revised form November 12, 2009. 